\title{
Human purine metabolism: some recent advances and relationships with immunodeficiency
}

\author{
GEORGE N UK I \\ From the Rheumatic Diseases Unit, Department of Medicine (WGH), University of Edinburgh
}

Studies of human purine metabolism began some 200 years ago with Scheele's identification of uric acid as a constituent of a renal calculus ${ }^{1}$ and Wollaston's demonstration of urate in a tophus from his own ear. ${ }^{2}$ Just as these were among the earliest experiments in the new science of biochemistry, so Garrod's $(1854)^{3}$ thread test must rank as the first assay in what we now call the discipline of clinical chemistry. Seegmiller's discovery, 15 years ago, that the severe purine overproduction and gout observed in boys with Lesch-Nyhan syndrome resulted from a specific defect of the purine salvage enzyme hypoxanthine-guanine phosphoribosyl transferase (HGPRT) ${ }^{4}$ led to what has been described as the 'purine revolution' and was soon followed by the identification of other inborn errors of metabolism associated with primary purine overproduction and gout. Oxypurine and deoxypurine bases, nucleosides, and nucleotides do, however, have much wider physiological importance as intermediates in energy metabolism, components of coenzymes, vasoactive and neurotransmitter substances, mediators of hormonal action, and as the building blocks for transmitters of genetic information (DNA and RNA). Most recently interest has been focused on the role of purines, and especially deoxypurines, in the regulation of immune responses.

\section{Gout and hyperuricaemia}

In most individuals with gout or asymptomatic hyperuricaemia the rise in serum urate concentration is the result of a decrease in renal urate clearance. In $15 \%$ or less there is evidence of excessive purine synthesis and hyperuricosuria. A 24-hour urinary urate excretion greater than
$0.6 \mathrm{~g}(3.6 \mathrm{mmol})$ while on a $10.9 \mathrm{MJ}$ (2600 kilocalorie), $70 \mathrm{~g}$ protein, purine-free diet is generally taken to be abnormal, ${ }^{5}$ but recent data on healthy Australians on low purine diets showed mean urinary urates of $3.9 \mathrm{mmol}(0.65 \mathrm{~g}) / 24 \mathrm{hrs}$ for men and $2.9 \mathrm{mmol}(0.5 \mathrm{~g}) / 24 \mathrm{hrs}$ for women. ${ }^{6}$

A variety of mutations of three enzymes are associated with excessive purine synthesis in patients with gout, but these account for only a small proportion of those identified as primary overproducers of urate.

Purine nucleotide synthesis in mammalian cells is regulated by a

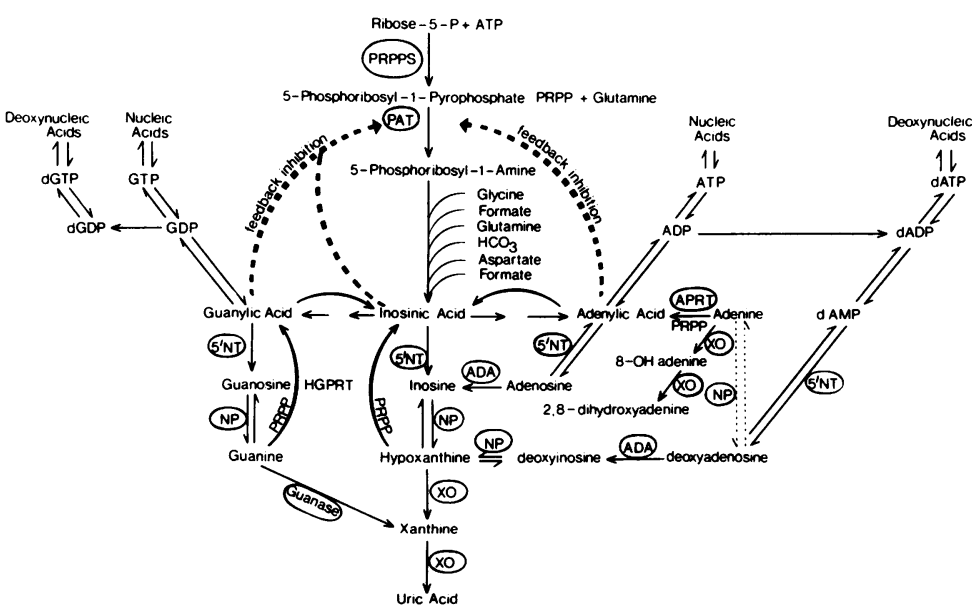

Fig. 1 Pathways of purine metabolism in man.

ADA $=$ Adenosine deaminase.

APRT $=$ Adenine phosphoribosyl transferase.

HGPRT = Hypoxanthine-guanine phosphoribosyl transferase.

NP $\quad=$ Nucleoside phosphorylase.

5'NT $=5$ 'nucleotidase

PAT $=$ Phosphoribosyl pyrophosphate amidotransferase.

PPRPS = Phosphoribosyl pyrophosphate synthetase.

$\mathrm{XO}=$ Xanthine oxidase.

Reproduced from: Nuki G, Advanced Medicine 15. London: Pitman Medical, 1979: 140 with permission of publishers. balanced interaction of several biochemical pathways (Fig. 1). Purine biosynthesis de novo consists of a 10 enzymatic steps in which aspartate, glycine, carbon dioxide, derivatives of folate are added to the ribose moiety of phosphoribosyl pyrophosphate (PRPP) to form (IMP). Adenosine guanosine monophosphate (GMP) are each formed from IMP by two enzymatic steps before phosphorylation to their respective diphosphates and triphosphates. Alternatively, the 
nucleotide monophosphates may be synthesised by phosphorylation of purine bases by phosphoribosyl transferase enzymes reacting with PRPP, and AMP may be formed by phosphorylation of adenosine by adenosine kinase. In vitro studies of amido phosphoribosyl transferase (PAT), the first enzyme in the de novo pathway, show it to have allosteric properties that one often associates with a rate-limiting enzyme, and have provided a molecular model for the mechanism whereby the rate of purine nucleotide synthesis may be regulated. The protein exists in two forms; an inactive dimer and a catalytically active monomer. PRPP converts the larger form of the enzyme to the active monomer, while purine nucleotide monophosphates have the reverse effect. $^{7}$

\section{HGPRT deficiency}

In Lesch-Nyhan syndrome and the severe familial form of $\mathrm{X}$-linked gout, which is also associated with deficiency of HGPRT, it seems logical to conclude that the considerably accelerated rate of de novo purine synthesis results from both accumulation of PRPP and diminished feedback inhibition of PAT by purine nucleotides. However, while intracellular concentrations of PRPP are increased in HGPRT-deficient cells, steady state purine nucleotide concentrations do not appear to be reduced, ${ }^{89}$ and concentrations of pyrimidine nucleotides are actually increased. ${ }^{9}$ A good deal of evidence suggests that PRPP, which is present in cells at limiting concentrations, is the major regulator of rates of de novo purine synthesis whenever purine overproduction occurs in vivo. On the other hand, the importance of purine base 'salvage' is emphasised by experiments which show that rates of purine synthesis in normal human lymphoblasts may be increased to those observed in HGPRT-deficient mutants if hypoxanthine is carefully excluded from the culture medium. ${ }^{10}$ Moreover, Hershfield has demonstrated co-ordinated inhibition of IMP conversion to adenine nucleotides with enhancement of total guanine nucleotide synthesis after the addition of adenosine to human lymphoblasts in culture, emphasising the potential regulatory importance of the distal inosinic acid branch point. ${ }^{11}$

There is increasing evidence of genetic heterogeneity at the HGPRT locus. ${ }^{1213}$ Although the severity of clinical manifestations is usually proportional to the severity of the enzyme defect, this is not always apparently the case. In rare instances mutations resulting in abnormal enzyme kinetics may be associated on the one hand with the classic clinical Lesch-Nyhan phenotype and apparently normal red cell HGPRT activity assayed at saturating substrate concentrations, or on the other hand with X-linked gout without neurological features and apparently absent enzyme activity in standard assays. Immunochemical studies have shown that most mutations at the HGPRT locus are structural gene mutations resulting in catalytically defective enzyme protein that does not cross react with antibody raised against highly purified normal human HGPRT (CRM negative mutants). ${ }^{14}$

Recent studies have provided evidence for a single amino acid substitution in one such structural variant $\left(\right.$ HGPRT $\left._{\text {munich }}\right),{ }^{15}$ while other groups have now succeeded in cloning the HGPRT gene. ${ }^{1617}$

\section{APRT deficiency}

Adenine phosphoribosyl transferase deficiency is not associated with gout or purine overproduction. Although heterozygous, partial APRT deficiency was originally described in gouty patients it is clear from family studies that the enzyme defect and hyperuricaemia are inherited as independent traits. ${ }^{18}$ The apparent association arose spuriously because APRT enzyme assays were undertaken only in patients with gout, although heterozygous APRT deficiency may occur in as many as $1 \%$ of the population. ${ }^{19}$ More recently, a number of patients have been identified in whom severe, homozygous APRT deficiency was associated with symptomatic urinary lithiasis and calculi composed of 2 , 8-dihydroxyaden ine. ${ }^{2021} X$-ray diffraction, infrared and ultraviolet absorption spectrometry, and ion exchange chromatography of HPLC extracts of these stones have been required to differentiate the adenine metabolites from uric acid. ${ }^{21}$ These patients may be treated successfully with a low purine diet and allopurinol, ${ }^{22}$ which inhibits the formation of 2,8-dihydroxyadenine.

\section{Superactive PRPP synthetase}

Structural mutations resulting in superactive phosphoribosyl pyrophosphate synthetase are now well established as a cause of $\mathrm{X}$-linked gout and purine overproduction. Initially increased enzyme activity was associated with decreased sensitivity to feedback inhibition by purine nucleotides in one family ${ }^{23}$ and a primary increase in catalytic activity per enzyme molecule of the mutant protein in another. ${ }^{24}$ More recently the genetic heterogeneity and diversity of abnormalities in kinetic mechanisms leading to superactivity of this enzyme has been extended to include mutants with increased $\mathrm{V}$ max, various abnormalities of purine nucleotide feedback inhibitor responsiveness, increased affinity for the substrate ribose-5phosphate, and a combination of catalytic and regulatory defects. ${ }^{25}$

Most affected males have presented with gouty arthritis and/or uric acid urolithiasis in early adult life, but two families have been described where homozygous boys developed symptoms in childhood and shared metabolic abnormalities and nerve deafness with their heterozygous mothers. ${ }^{26} 27$

\section{Type I glycogen storage disease}

Glucose-6-phosphatase deficiency is associated with both overproduction and underexcretion of uric acid, so that gout and hyperuricaemia become appreciable clinical problems in affected individuals fortunate enough to survive to adult life. Persistent lactic acidaemia is the major cause of impairment of uric acid excretion and the simultaneous increase in de novo purine synthesis observed in these patients is thought to result from excessive production of PRPP after 'shunting' of metabolites through the pentose phosphate pathway. ${ }^{28}$ It has been difficult to test this hypothesis direct, as glucose-6-phosphatase activity is limited to the liver, kidney, and intestinal mucosa. Recently it has been suggested that increased purine 
production in this disorder may be secondary to accelerated purine degradation after recurrent glycogenolysis and depletion of ATP $^{29}$; rather like the mechanism accounting for the purine overproduction and hyperuricaemia which follow ingestion or infusion of fructose..$^{30}$ Van den Berghe and his colleagues believe that the hepatic catabolism of adenine nucleotides and the formation of uric acid are regulated by the activity of AMP deaminase. ${ }^{31}$

Type I glycogen storage disease is usually characterised by complete absence of hepatic glucose-6phosphatase. We have recently reported the case of a child with a partial enzyme deficiency where there was a striking absence of hypoglycaemia. ${ }^{32}$ This suggests that type I glycogen storage disease with partial deficiency of hepatic glucose-6-phosphatase should perhaps be considered in patients with gout or hyperuricaemia associated with hypertriglyceridaemia and lactic acidaemia, even in the absence of hypoglycaemia.

\section{Other enzyme defects and gout}

We are still unable to define the metabolic abnormality responsible for purine overproduction in most of the few patients with gout who are primary hyperexcretors of uric acid. Though some of these may well be attributable to subtle kinetic variations of known enzyme defects not detectable in standard in vitro assays, it seems probable that other primary purine enzyme defects remain to be discovered. For example, in vivo ${ }^{33}$ and in vitro ${ }^{34}$ studies with drugs that inhibit IMP dehydrogenase suggest that deficiency of this enzyme might well be associated with primary purine overproduction.

PURINE ENZYME

ABNORMALITIES AND

IM M U NODEFICIENCY

A great deal of interest has been recently aroused by the association of two inborn errors of purine metabolism with immune deficiency syndromes.

Severe deficiency of adenosine deaminase (ADA) was first reported in red cell haemolysates from two children with severe combined immunodeficiency in $1972 .{ }^{35}$ Three years later Eloise Giblett also reported a gross deficiency of red cell purine nucleoside phosphorylase (PNP) in children with recurrent infections and a predominant $\mathrm{T}$-lymphocyte deficiency. ${ }^{36}$

The causal relationship between these inherited enzyme abnormalities and the immunodeficiency syndromes is now established and has highlighted the need for an intact purine catabolic pathway to maintain normal cellular and humoral immunity. In patients with deficiencies of ADA and PNP plasma concentrations of deoxyadenosine $^{37}$ and deoxyguanosine ${ }^{38}$ are raised. These deoxynucleosides are selectively phosphorylated and trapped by $\mathrm{T}$-lymphocytes with high activities of deoxycytidine kinase and low activities of intracellular deoxynucleotidase. As a result deoxyadenosine $^{39}$ and dexoyguanosine ${ }^{40}$ accumulate in the cells, leading to inhibition of ribonucleotide reductase and DNA synthesis. An alternative mechanism for the toxicity of deoxyadenosine in ADA deficiency has been proposed by Hershfield, ${ }^{41}$ who showed that it causes irreversible 'suicide' inactivation of the enzyme S-adenosyl homocysteine hydrolase. Consistent with this hypothesis S-adenosyl homocysteine hydrolase activity is found to be considerably reduced in the red cells of children with ADA deficiency, ${ }^{42}$ but an alternative explanation needs to be found to explain the T-cell deficiency in PNP deficiency, as deoxyguanosine does not inhibit the S-adenosyl homocysteine hydrolase enzyme.

To explain the difference in the immunodeficiency syndromes associated with ADA and PNP deficiency, evidence has recently been produced to show that intracellular ATP activities are depleted with accumulation of deoxyadenosine but not with deoxyguanosine, so killing the non-dividing helper T-lymphocytes. ${ }^{43}$ Humoral immunity persists in patients with PNP deficiency because T-helper function is relatively proliferation independent.

Decreased activity of the ectopurine $5^{\prime}$ nucleotidase ( $5^{\prime} \mathrm{NT}$ ) enzyme has been associated with $\mathrm{X}$-linked ${ }^{44}$ and acquired adult onset (common variable) hypergammaglobulinaemia. ${ }^{45}$ Deficiency of this enzyme does not, however, result from a primary gene mutation and there is no evidence to suggest that it is causally related to B-cell deficiency. 5'NT deficiency in $\mathrm{X}$-linked agammaglobulinaemia largely reflects the deficit in circulating B-cells which have high 5'NT activity. B-cell numbers are, however, almost normal in common variable hypogammaglobulinaemia and in this situation it seems likely that reduction in $5^{\prime} \mathrm{NT}$ is associated with a population of relatively immature B-lymphocytes. $5^{\prime}$ NT has been previously shown to be a marker of differentiation in both $\mathrm{T}^{46}$ and $\mathrm{B}^{47}$ lymphocytes.

\section{References}

1 Scheele K W. Examen chemicum calculi urinarii. Opuscula 1976; 73: 2.

2 Wollaston W H. On gouty and urinary concretions. Philos Trans $R$ Soc Lond 1797; 87: 386.

3 Garrod A B. On the blood and effused fluids in gout, rheumatism and Bright's Disease. Transactions of the Medico-Chirugical Society of Edinburgh 1854; 37: 49.

4 Seegmiller J E, Rosenbloom F M, Kelley W N. Enzyme defect associated with a sex-linked neurological disorder and excessive purine synthesis. Science 1967; 155: 1682-4.

5 Seegmiller J E, Grayzel A I, Laster L, Liddle $\mathrm{L}$. Uric acid production in gout.J Clin Invest 1961; 40: 1304-14.

6 Stafford W, Emmerson B T. Effect of purine restriction on serum and urinary urate (Abstract). J Clin Chem Clin Biochem 1982; 20: 422-3.

7 Holmes E W, Wyngaarden J B, Kelley W N. Human glutamine, phosphoribosyl pyrophosphate amido transferase: two molecular forms interconvertible by purine ribonucleotides and phosphoribosyl pyrophosphate. $J$ Biol Chem 1973; 248: 6035-40.

8 Rosenbloom F M, Henderson J F, Caldwell I C, Kelley W N, Seegmiller J E. Biochemical bases of accelerated purine biosynthesis de novo in human fibroblasts lacking hypoxanthine-guanine phosphoribosyl transferase. J Biol Chem 1968; 243: 1166-73.

9 Nuki G, Astrin K, Brenton D, Cruikshank M, Lever L, Seegmiller J E. Purine and pyrimidine nucleotide concentrations in cells with decreased hypoxanthine-guanine phosphoribosyl transferase (HGPRT) activity. Adv Exp Med Biol 1977; 76A: 326-9.

10 Hershfield M S, Seegmiller J E. Regulation of de novo purine synthesis in human lymphoblasts: similar rates of de novo synthesis during growth by normal cells and mutants deficient in hypoxanthine-guanine phosphoribosyl 
transferase activity. J Biol Chem 1977; 252: 6002-10.

11 Hershfield M S, Seegmiller J E. Regulation of de novo purine biosynthesis in human lymphoblasts: co-ordinate control of proximal rate determining steps and the inosinic acid branch point. J Biol Chem 1976; 251: 7348-54.

12 Emmerson B T, Thompson L. The spectrum of hypoxanthine-guanine phosphoribosyl transferase deficiency. $Q J$ Med 1973; 42: 423-40.

13 Nyhan W L. Genetic heterogeneity at the locus for hypoxanthine-guanine phosphoribosyl transferase. In: Purine and pyrimidine metabolism, Ciba Foundation Symposium No 48 . Amsterdam. Excerpta Medica: 65-81.

14 Upchurch K S, Leyva A, Arnold W J, Holmes E W, Kelley W N. Hypoxanthine phosphoribosyl transferase deficiency: association of reduced catalytic activity with reduced levels of immunologically detectable enzyme protein. Proc Natl Acad Sci USA 1975; 72: 4142-6.

15 Wilson J M, Tait G E, Grobner W, ZolIner N, Kelley W N. Evidence for an amino acid substitution (Ser Arg) in the hypoxanthine-guanine phosphoribosyl transferase variant HGPRT $_{\text {munich }}$ (Abstract).J Clin Chem Clin Biochem 1982;

16 Jolly D J, Esty A, Friedmann T. The cloned human hypoxanthine-guanine phosphoribosyl transferase gene (Abstract). J Clin Chem Clin Biochem 1982; 20: 380.

17 Chinault A C, Konecki D S, Brennand J, Patel P, Melton D W, Caskey C T. Cloning and characterisations of mammalian hypoxanthine-guanine phosphoribosyl transferase genes (Abstract). J Clin Chem Clin Biochem 1982; 20: 442.

18 Emmerson B T, Gordon R B, Thompson L. Adenine phosphoribosyl transferase deficiency in a female with gout. Adv Exp Med Biol 1974; 41: 327-31.

19 Fox I H, Lacroix S, Planet G, Moore N. Partial deficiency of adenine phosphoribosyl transferase in man. Medicine 1977; 56: 515-26.

20 Cartier M B, Hanset M. Une nouvelle maladie metabolique: le deficit complex en adenine phosphoribosyl transferase avec lithiase de 2, 8-dihydroxyadenine. Comptes Rendus Hebdomadaires des Séances de l'Académie des Sciences (Paris) 1974; 270: 883-6.

21 Simmonds H A, Van Acker K J, Cameron J S, Sneddon $W$. The identification of 2, 8-dihydroxyadenine, a new component of urinary stones. Biochem J 1976; 157: 485-7.

22 Simmonds H A, Van Acker K J, Cameron J S, McBurney A. Purine excretion in complete adenine phosphoribosyl transferase deficiency: effect of diet and allopurinol therapy. Adv Exp Med Biol 1977; 76B: 304-11.

23 Sperling Q, Persky-Brosh S, Boer P, De Vries A. Human erythrocyte phosphoribosyl pyrophosphate synthetase mutationally altered in relatory properties. Biochem Med 1973; 7: 389-95.

24 Becker M A, Kostel P J, Meyer L J, Seegmiller J E. Human phosphoribosyl pyrophosphate synthetase: increased enzyme activity in a family with gout and excessive purine synthesis. Proc Natl Acad Sci USA 1973; 70: 2749.

25 Becker M A. Phosphoribosyl pyrophosphate synthetase superactivity: detection, characterization of underlying defects and treatment (Abstract). $J$ Clin Chem Clin Biochem 1982; 20: 347.

26 Becker M A, Raivio K O, Bakay B, Adams W B. Variant human phosphoribosyl pyrophosphate synthetase altered in regulatory and catalytic functions. J Clin Invest 1980; 65: 109-20.

27 Simmonds H A, Webster D R, Wilson J, Lingham $\mathrm{S}$. An $\mathrm{X}$-linked syndrome characterised by hyperuricaemia, deafness and neurodevelopmental abnormalities. Lancet 1982; ii: 68-70.

28 Howell $\mathbf{R} R$. The interrelationship of colycogen storage disease and gout. Arthritis Rheum 1965; 8: 780-5.

29 Greene HC, Wilson F A, Hefferan P, et al. ATP depletion, a possible role in the pathogenesis of hyperuricaemia in glycogen storage disease type I. J Clin Invest 1978; 62: 321-8.

30 Raivio K O, Becker M A, Meyer L J, Greene M L, Nuki G, Seegmiller J E. Effects of fructose infusion on urate production in man. Metabolism 1975; 24: 861-9.

31 Van den Berghe G, Bronfman $M$, Vanneste R, Hers H G. The mechanism of adenosine triphosphate depletion in the liver after a load of fructose. Biochem J 1977; 162: 601-9.

32 Nuki G, Parker J. Clinical and enzymological studies in a child with type I glycogen storage disease associated with partial deficiency of hepatic glucose-6-phosphatase. Adv Exp Med Biol 1979; 122A: 189-202.

33 Seegmiller J E, Grayzel A I, Liddle L, Wyngaarden J B. The effect of 2-ethyl-amino-1,3,4-thiadizole on the incorporation of glycine into urinary purines and uric acid in man. Metabolism 1963; 12: 507-15.

34 Willis R C, Carson D A, Seegmiller J E. Adenosine kinase initiates the major route of ribavirin activation in a cultured human cell line. Proc Natl Acad Sci USA 1978; 75: 3042-4.

35 Giblett E R, Anderson J E, Cohen F, Pollara B, Menwissen H J. Adenosine deaminase deficiency in two patients with severely impaired cellular immunity. Lancet 1972; ii: 1067-9.

36 Giblett E R, Ammann A J, Warn D W,
Sandiman R, Diamond L K. Nucleoside phosphorylase deficiency in a child with severely defective T-cell immunity and normal B-cell immunity. Lancet 1975; i: $1010-3$.

37 Simmonds H A, Panayi G S, Corigal V. A role for purine metabolism in the immune response, adenosine de aminase activity and deoxyadenosine catabolism. Lancet 1978; i: 60-3.

38 Cohen A, Doyle D, Martin D W Jr, Ammann A J. Abnormal purine metabolism and purine over-production in a patient deficient in purine nucleoside phosphorylase. $N$ Engl $J$ Med 1976; 295: 1449-54.

39 Donofino J, Coleman M S, Hutton J J, Duoud A, Lomplein B, Difminski J. Over production of adenine deoxynucleosides and deoxynucleotides in adenosine deaminase deficiency with severe combined immunodeficiency disease. J Clin Invest 1978; 62: 884.

40 Cohen A, Goudas L J, Ammann A J, Staal G E J, Martin D W Jr. Deoxyguanosine tri-phosphate as a possible toxic metabolite in purine nucleoside phosphorylase deficiency. $J$ Clin Invest 1978; 61: 1405.

41 Hershfield M S. Suicide inactivation of human lymphoblast S-adenosyl homocysteine hydrolase by 2 '-deoxyadenosine and adenine arabinoside: a basis for direct toxic effects of analogs of adenosine. $J$ Biol Chem 1979; 254: 22.

42 Hershfield $M S$, Knedich $N$, Ownby D R, Ownby H, Buckley R J. In vivo inactivation of erythrocyte S-adenosyl homocysteine hydrolase by 2 '-deoxyadenosine in adenosine deaminase deficient patients. J Clin Invest 1979; 63: 807.

43 Carson D A, Wasson D B, Lakow E, Kamatami M. Biochemical basis for lymphocyte dysfunction in adenosine deaminase and purine nucleoside phosphorylase deficiencies.J Clin Chem Clin Biochem 1982; 20: 355.

44 Edwards M L, Magilavy D B, Cassidy J T, Fox I H. Lymphocyte ecto-5' nucleotidase deficiency in agammaglobulinaemia. Science 1978; 201: 628-30.

45 Johnson $S$ M, North M E, Asherson $G$ L, Allsop J, Watts R W E, Webster A D B. Lymphocyte purine 5 -nucleotidase deficiency in primary hypogammaglobulins. Lancet 1977; i: 168-70.

46 Edwards M L, Gelfund E W, Burk L, Dosch H M, Fox I H. Distribution of 5' nucloeotidase in human lymphoid tissues. Proc Natl Acad Sci USA 1979; 76: 3474-6.

47 Boss G R, Thompson L F, Spregelheng $\mathrm{H} \mathrm{L}$, et al. Lymphocyte ecto-5' nucleotidase activity as a marker of B-cell maturation. Trans Assoc Am Physicians 1979; 92: 309-15. 